\title{
Acupuncture in the treatment of acute toxicity during and after head and neck cancer radiotherapy: Interim analysis of randomized prospective open-label trial
}

\author{
Radana Dymackova ${ }^{\mathrm{a}, \mathrm{b}}$, Tomas Kazda ${ }^{\mathrm{a}, \mathrm{b}}$, Marek Slavik ${ }^{\mathrm{a}, \mathrm{b}}$, Iveta Selingerovac, Pavel Slampa ${ }^{\mathrm{a}, \mathrm{b}}$, Ondrej Slama ${ }^{\mathrm{d}, e}$
}

\begin{abstract}
Aims. The aim of this investigator-initiated prospective randomized open-label single institutional trial is to evaluate the role of acupuncture in the treatment of acute skin and mucosal toxicity, xerostomia, and perception of taste, pain, and nausea related to curative and adjuvant (chemo)radiotherapy of head and neck cancer. This paper reports pilot data of the first 30 enrolled patients.

Methods. Patients were randomized to undergo standard of care radiotherapy \pm chemotherapy and support care defined by our institutional standard operating procedures alone or in the combination with acupuncture which was initiated with the first signs of any toxicity.

Results. Fifteen patients were enrolled in both arms and all finished the treatment as planned.The median pain was significantly lower in the acupuncture arm (median 1.6 points vs. 2.5 points on a 10 -item Likert scale; $P=0.035$ ) as well as duration of acute pain (median 31 days vs. 54 days; $P=0.031$ ). Patients with acupuncture had significantly shorter duration of acute skin (median 44 days vs. 109 days; $P<0.001$ ) and mucosal toxicity (median 34 days vs. 109 days; $P<0.001$ ) with no difference in grading of toxicity (median grade 1.6 vs. 1.5; $P=0.701$ and median grade 1.4 vs. 1.6; $P=0.204$ for skin and mucosa, respectively). No significant difference was found for other toxicity domains, with the exception of salivation toxicity which was significantly lower in acupuncture arm (median grade 1.3 vs. $1.7 ; P=0.048$ ).

Conclusion. In this interim analysis, acupuncture leads to lower pain andfaster disappearance of skin and mucosal toxicity after (chemo)radiotherapy of head and neck cancer. Description and validation of acupuncture using scientific approaches will further enhance acceptance of this method by both patients and health care providers.
\end{abstract}

Trial Registration: Clinicaltrials.gov - NCT03751566

Key words: acupuncture, head and neck, cancer, radiotherapy, toxicity

Received: July 10, 2019; Revised: April 25, 2020; Accepted: April 30, 2020; Available online: June 18, 2020

https://doi.org/10.5507/bp.2020.021

(c) 2020 The Authors; https://creativecommons.org/licenses/by/4.0/

${ }^{a}$ Department of Radiation Oncology, Faculty of Medicine, Masaryk University, Kamenice 5, 62500 Brno, Czech Republic ${ }^{b}$ Department of Radiation Oncology, Masaryk Memorial Cancer Institute, Zluty kopec 7, 65653 Brno, Czech Republic

'Regional Center for Applied Molecular Oncology (RECAMO), Masaryk Memorial Cancer Institute, Zluty kopec 7, 656 53 Brno, Czech Republic ${ }^{d}$ Department of Comprehensive Cancer Care, Faculty of Medicine, Masaryk University, Kamenice 5, 62500 Brno, Czech Republic eDepartment of Comprehensive Cancer Care, Masaryk Memorial Cancer Institute, Zluty kopec 7, 65653 Brno, Czech Republic Corresponding author: Tomas Kazda, e-mail: tomas.kazda@mou.cz

\section{INTRODUCTION}

Curative, as well as postoperative adjuvant radiotherapy (RT) is the cornerstone in the treatment of patients with head and neck cancer ${ }^{1}$. Besides high efficacy, this RT as well as concomitant chemotherapy is related to severe acute and chronic toxicity in almost all irradiated patients, influencing patients' compliance and adherence to treatment as well as quality of life in patients with long survival. The side effects are even more prominent with concomitant chemotherapy administration. Aggressive supportive and prophylactic care aimed at the amelioration and postponing of acute toxicity is an integral part of comprehensive care. Among others, the most important is prophylaxis and treatment of therapy-related radiodermatitis, mucosal inflammation (often requiring prophylactic percutaneous endoscopic gastrostomy), change in salivation and perception of taste. During the treatment, patients also suffer from pain and nausea.
Acupuncture is a part of complementary and alternative Traditional Chinese Medicine (TCM) therapy. It involves the insertion of very thin needles through the skin at defined points on the body. It is most commonly used to treatpain but also for overal well being and stress management, various mental and physical conditions including amelioration of the side effects of standard cancer therapy including RT ( ref. $^{2-4}$ ).

Chinese medicine explains acupuncture as a means for balancing the flow of energy through the body. The needles are inserted along the energy lines called meridians $^{5,6}$. These are connected to intrinsic organs. The function of many different parts of the human body is assumed to be influenced by stimulation of the meridians by fine needles (acupuncture), by pressure (acupressure) or by moxibustion (warming) ( ref. $^{7}$ ).

The aim of this investigator-initiated prospective randomized open-label single institutional trial is to evaluate the role of acupuncture in the treatment of acute skin and mucosal toxicity, xerostomia, and perception of taste, 
pain, and nausea related to curative and adjuvant (chemo) radiotherapy of head and neck cancer. This paper reports pilot data of first 30 enrolled patients. The study was approved by the institutional review board.

\section{MATERIALS AND METHODS}

\section{Patients selection and randomization}

Patients referred to the Department of radiation oncology, Masaryk Memorial Cancer Institute, for curative or adjuvant RT of newly diagnosed head and neck cancer from March 2016 to June 2017 were screened for eligibility criteria. Inclusion criteria were age $>18$ years, Karnofsky performance status $\geq 60 \%$, physical and mental competence (as assessed subjectively by investigator) to manage the therapy diary for toxicity records. Exclusion criteria were enrollment in another clinical trial and palliative intent of the treatment with lower prescribed dose of RT. After signature of informed consent, patients were enrolled into the study and randomized to control or intervention arm by permuted stratified block randomization (block size 4). The stratification factors included aim of radiotherapy (curative vs. adjuvant) and planned chemotherapy administration (yes vs. no). All enrolled patients underwent standard of care (chemo)radiotherapy and supportive care defined by our institutional standard operating procedures. Patients enrolled into intervention arm received additional acupuncture.

\section{Standard of care}

Radiotherapy of enrolled patients was fully managed by treating physicians, not exclusively by the investigators. With the daily dose of $2 \mathrm{~Gy}$ (or in simultaneous integrated boost 1.6-2.12 Gy daily dose), the total dose of 66 to 70 Gy was prescribed to the tumor and pathological lymph nodes in curative RT and the total dose of 50-60 Gy in adjuvant approach (with possible boost to 64-66 Gy in the case of postoperative risk factors as is positive resection margin or proved extracapsular extension). Elective dose to different lymph node regions was prescribed according to individual clinical situation based on current guidelines ${ }^{1,8,9}$. All patients were treated by modern methods of photon radiotherapy - intensity modulated arc RT delivered by linear accelerator (Varian, Palo Alto, California, USA; volumetric modulated RapidArc technique) with the aim to spare organs at risk as much as reasonably possible.

Chemotherapy was indicated in patients with presented risk factors (large size of primary tumor, lymphatic nodes involvement, higher grading). Risk factors after operation included also positive resection margins and extracapsular extension. Cisplatin was administrated weekly (30-40 mg/m $\mathrm{m}^{2}$ ) or on days 1,22 and $43\left(100 \mathrm{mg} / \mathrm{m}^{2}\right)$. Carboplatin weekly (AUC 1.5) was administrated in patients with contraindication to cisplatin.

Standard supportive care started with proper education of all patients before treatment with the aim to start prophylaxis onthe same day as RT. The care for irradiated skin consisted mainly of daily treatment with an oint- ment containing calcium panthotenicum, dexpanthenol, hyaluronic acid, etc. (and of prevention by wearing appropriate loose collar clothing for example). Mucositis was treated and prophylacted by mouth disinfection containing for example chlorhexidine, benzydaminehydrochloridum or sage tea and mouthwash solution such as Caphosol or Gelclaire. The care for mucosa included education for diet to soft foods and recommendation to usage of extrasoft toothbrush. Based on individual clinical need, the appropriate analgesics were prescribed (often in the form of drops) ranging frommetamizole, tramadol or paracetamol to transdermal fentanyl or buprenorphine (including also sucking of ice cubes for example) as well as appropriate antiemetics (metoclopramide or setrons), treatment of oedema (escinum alfa) or infusion therapy for rehydration. Prophylaxis of swallowing difficulties was performed by dieting with soft meals, taking lots of fluids, avoiding hot fluids and avoiding sharp and spicy foods. Every patient was recommended to stop smoking and drinking alcohol during the treatment.

\section{Acupuncture}

Acupuncture was provided by certified caregiver (R.D.) and began with the first signs of any toxicity. Disposable fine needles were applied two times a week during the RT. It was possible to continue in acupuncture for additional 1-2 months after RT in weekly or fortnightly regimen according to patient's needs and severity of toxicity. The needles were applied in an individual manner also with respect to the tongue picture and heart pulsation ${ }^{10}$. The duration of one session was 10-20 min. The points for needle insertion were chosen also with the aim to be outside the irradiated skin but included points on the face or ear acupuncture (the master points, point related to taste sense or to local face or neck points). It was possible to continue acupuncture after the end of radiotherapy with the aim of decreasing late toxicity as well.

\section{Toxicity assessment}

Acute toxicity (up to 3 months after the end of RT) was evaluated during RT by patients daily (including making records) and by physician weekly. After the end of RT, the side effects were assessed daily for one month by patients and ones after first and after third month by the physician. Skin and mucosal toxicity were graded according to Radiation Therapy Oncology Group (RTOG) (ref. ${ }^{11}$ ) on the scale ranging from 1 (weak erythema, asymptomatic) to 4 (exfoliative dermatitis or ulceration). Pain and nausea were assessed using a 10-item Likert scale. In the case of no pain, the value "zero" was recorded. Duration of pain was calculated within three months after radiotherapy as a number of days with pain on the Likert scale greater than 0 . The loss of taste was scored dichotomically as full or partial. Salivary gland toxicity was graded as skin toxicity on a scale ranging from 1 (slightly dryness) to 4 (total dryness). Taste was graded as changes in taste or loss of taste. For each patient, the average grade or Likert scale score per day was calculated for both arms. The duration of side effects was recorded as well. 


\section{Statistical Analysis}

Frequency tables and descriptive statistics were employed for description of initial patients' demographics and characteristics. The association between categorical variables was evaluated by Fisher's exact test. The MannWhitney test was used to compare medians in the two groups and differences between groups were graphical presented using box plots. All significance testing was performed at the 0.05 level; $R$ software version 3.5.1 was used for all analyses.

\section{RESULTS}

\section{Patients' characteristics}

Total of 229 patients was evaluated for eligibility criteria, $63 \%$ of those being eligible agreed with the enrollment. From March 2016 to June 2017, 30 patients were enrolled ( 15 in each arm) and are subjects of the presented interim analysis (Fig. 1). The most common reason for refusal of enrollment was anticipated needle intolerance or reluctance to undergo another additional time-consuming procedure. Some patients expressed the wish to be just enrolledin the control arm, however, this was not allowed based on the predetermined study protocol. One of the most common exclusion criteriawas enrollment to another clinical trial. The median age was 57 years, $73 \%$ of enrolled patients were men. Patients in the acupuncture arm were younger (median 52 vs. 60 years, $P=0.036$ ). Patients in the acupuncture arm were mainly non-smokers. Patients in the control arm were mainly smokers. More patients with adjuvant radiotherapy and less concomitant chemotherapy were in the acupuncture arm. Median follow up is 20.4 months. The other basic patient characteristics are summarized in Tables 1-3.

\section{Therapy including acupuncture}

All patients finished the treatment as planned. Details ofthe treatment are listed in Table 4. Two patients (one in each randomized arm) were lost from follow up and did not have any control examination or diary data on duration of acute toxicity. All 15 patients randomized to acupuncture arm finished the treatment as planned, 14 (93\%) continued with acupuncture several months after the end of RT. Acupuncture continued with the aim of reducing both acute and chronic adverse events.

\section{Toxicity evaluation}

Acute pain

Patients in the acupuncture arm had better control of acute pain. The median pain was significantly lower in the acupuncture arm (median 1.6 points vs. 2.5 points on 10 -item Likert scale; $P=0.035$ ) as well as duration of acute pain (median 31 days vs. 54 days; $P=0.031$ ). Average per day and the worst acute pain for an individual patient was used for evaluation. Duration of pain was evaluated during radiotherapy and three months after it. The results are shown, together with other toxicity outcomes, in Fig. 2.

Table 1. Basic patients' characteristics.

\begin{tabular}{lccc}
\hline Characteristic & $\begin{array}{c}\text { Control arm } \\
\mathrm{n}=15\end{array}$ & $\begin{array}{c}\text { Acupuncture arm } \\
\mathrm{n}=15\end{array}$ & $P$ \\
\hline Age (years) & & & 0.036 \\
$\quad$ Median & 60 & 52 & \\
$\quad$ Range & $45-72$ & $32-77$ & 0.682 \\
Sex & & & \\
$\quad$ Men (n; \%) & $12 ; 80 \%$ & $10 ; 67 \%$ & 0.215 \\
Radiotherapy & & & \\
Curative (n; \%) & $6 ; 40 \%$ & $2 ; 14 \%$ & 0.215 \\
Adjuvant(n; \%) & $9 ; 60 \%$ & $13 ; 87 \%$ & \\
Chemotherapy & & & \\
Indicated (n; \%) & $5 ; 33 \%$ & $2 ; 14 \%$ & \\
Diagnosis (n; \%) & & & \\
Oropharyngeal cancer & $5 ; 33 \%$ & $8 ; 53 \%$ & \\
Hard palate & 0 & $1 ; 7 \%$ & \\
Nasopharyngeal cancer & 0 & $1 ; 7 \%$ & \\
Thyroid cancer & 0 & $1 ; 7 \%$ & \\
Cancer of the lip & $1 ; 7 \%$ & $1 ; 7 \%$ & \\
Parotid salivary gland cancer & 0 & $1 ; 7 \%$ & \\
Unknown primary & $1 ; 7 \%$ & $1 ; 7 \%$ & \\
Larynx & $6 ; 40 \%$ & $1 ; 7 \%$ & \\
Smoker status & $9 ; 60 \%$ & $9 ; 3 \% \%$ & \\
Smoker & $5 ; 35 \%$ & & \\
Stop-smoker & $1 ; 7 \%$ & & \\
Non-smoker & & & \\
\hline
\end{tabular}

n: numbers 


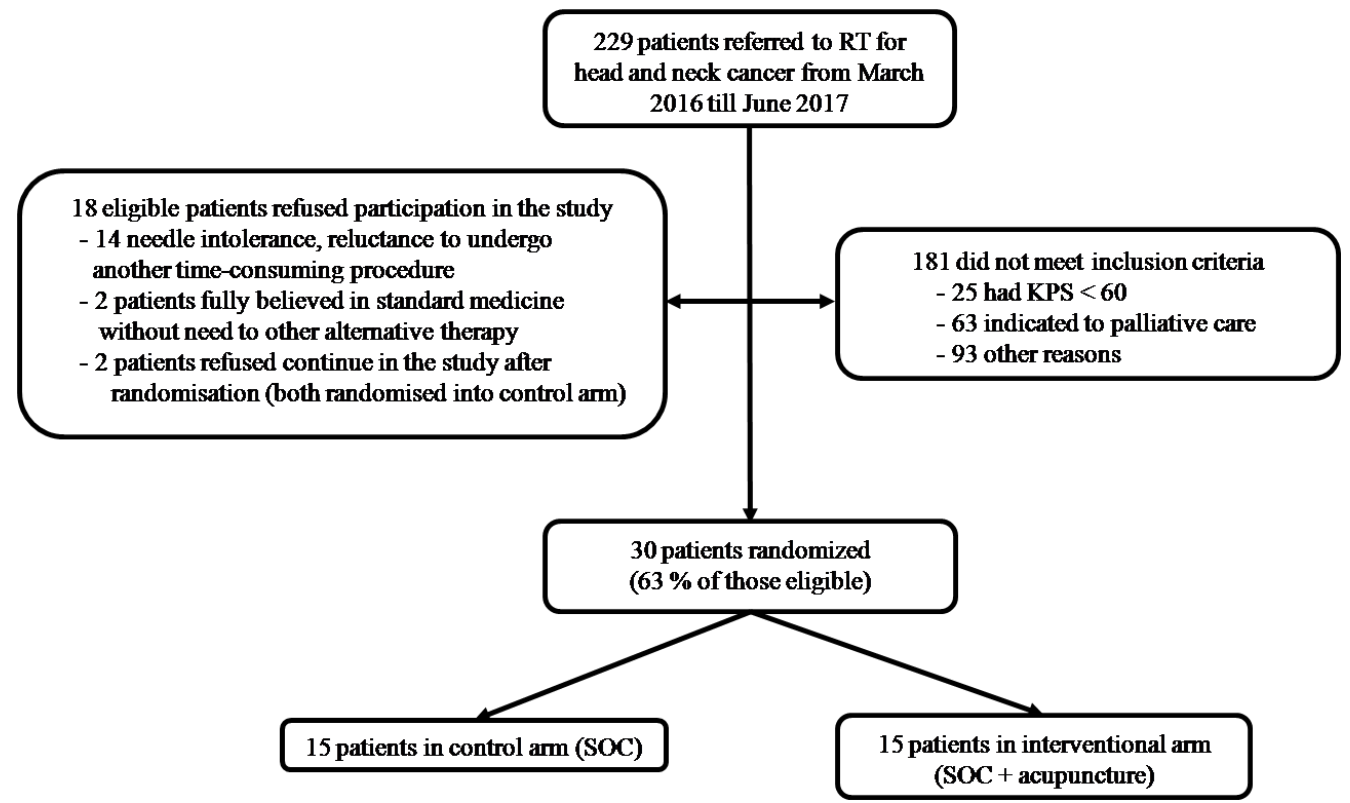

Fig. 1. Flow chart describing patients' enrollment into the study.

RT: radiotherapy; SOC: standard of care; KPS: Karnofsky performance status
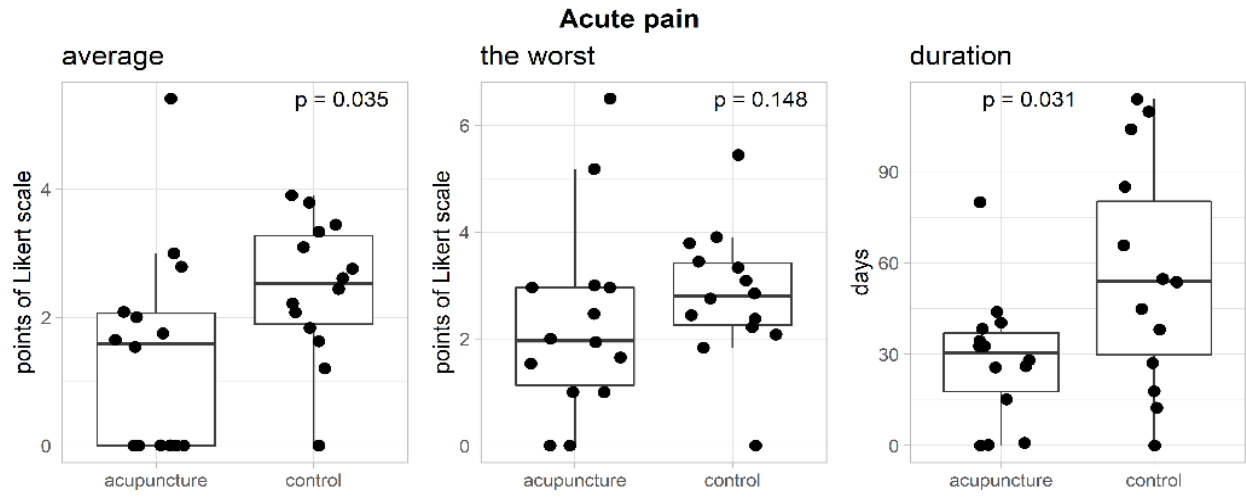

Skin toxicity
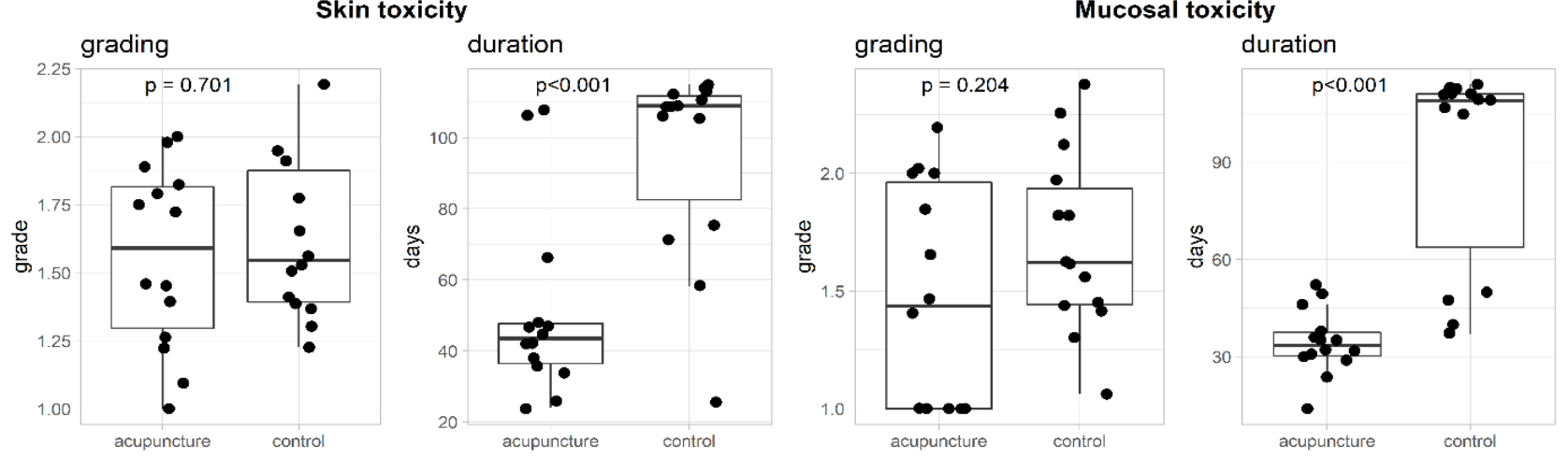

Fig. 2. Differences of outcomes in listed variables between standard treatment arm and patients with additional acupuncture.

Skin and mucosa - acute radiodermatitis and mucositis

Patients with acupuncture had significantly shorter duration of acute skin (median 44 days vs. 109 days; $P<0.001$ ) and mucosal toxicity (median 34 days vs. 109 days; $P<0.001$ ) with no difference in grading of toxicity (median grade 1.6 vs. $1.5 ; P=0.701$ and median grade 1.4 vs. 1.6; $P=0.204$ for skin and mucosa, respectively) (Fig. 2 ). For each patient, the average per day of grades is evaluated.
Nausea, taste perception and salivation

No statistically significant difference was found in the evaluation of maximal and average nausea (2.5 vs.0; $P=0.331$ and 0 vs. $0 ; P=0.740$, respectively), as well as induration of nausea or in the evaluation of treatment related changes of taste perception ( 21 vs. $0 ; P=0.136$ and 102 days vs. 105 days; $P=0.765$ ). Salivation toxicity was significantly lower in the acupuncture arm (median grade 1.3 vs. $1.7 ; P=0.048$ ). 
Table 2. Individual characteristics of patients from acupuncture arm: type of treatment, dose, volume of radiotherapy, target volume definition (PTV), chemotherapy.

\begin{tabular}{|c|c|c|c|c|c|}
\hline & $\begin{array}{l}\text { Curative/ } \\
\text { Adjuvant }\end{array}$ & Radiotherapy dose & $\begin{array}{l}\text { Volume of } \\
\text { prescribed dose } \\
\left(\mathrm{cm}^{3}\right)\end{array}$ & PTV & Chemotherapy \\
\hline 1 & adjuvant & $\begin{array}{l}30 \times 2 \mathrm{~Gy} \\
60 \mathrm{~Gy}\end{array}$ & 137.29 & bed of tumor & no \\
\hline 2 & curative & $\begin{array}{l}32 / 30 / 25 \times 2 \mathrm{~Gy} \\
64 / 60 / 50 \mathrm{~Gy}\end{array}$ & $\begin{array}{l}303.62 / \\
684.34 / \\
778.11\end{array}$ & $\begin{array}{l}\text { tu nasopharynx }+ \text { patol.LN/ } \\
\mathrm{LN} \mathrm{Ib}-\mathrm{V}+\text { paratrach. }+\mathrm{RP} \text { bilat./ } \\
\text { upper mediastinum }\end{array}$ & no \\
\hline 3 & adjuvant & $\begin{array}{l}30 x 2.1 / 1.8 / 1.65 \mathrm{~Gy} \\
60 / 54 / 49.5 \mathrm{~Gy}\end{array}$ & $\begin{array}{l}323.77 / \\
510.16 / \\
702.84\end{array}$ & $\begin{array}{l}\text { bed of gl.thyroidea+LN III+IV and supracl.sin/ } \\
\text { III+IV dx./ } \\
\text { upper mediastinum }\end{array}$ & no \\
\hline 4 & adjuvant & $\begin{array}{l}30 \times 2.1 / 2 / 1.8 \mathrm{~Gy} \\
63 / 60 / 54 \mathrm{~Gy}\end{array}$ & $\begin{array}{l}30.48 / \\
161.06 / \\
334.45\end{array}$ & $\begin{array}{l}\text { bed of tonsilla } \sin / \\
\mathrm{LN} \text { II }+\mathrm{III} \sin / \\
\mathrm{LN} \mathrm{Ia}+\mathrm{IV}+\mathrm{V}+\mathrm{RP} \sin \end{array}$ & $\begin{array}{l}\text { cisDDP } \\
\text { á } 3 \text { weeks } 1 \mathrm{x}\end{array}$ \\
\hline 5 & adjuvant & $\begin{array}{l}32 / 30 \times 2 \mathrm{~Gy} \\
64 / 60 \mathrm{~Gy}\end{array}$ & $\begin{array}{l}289.23 / \\
400.13\end{array}$ & $\begin{array}{l}\text { bed of relaps of tu upper lip l.sin with larger rim/ } \\
\text { with smaller rim }\end{array}$ & no \\
\hline 6 & adjuvant & $\begin{array}{l}30 \times 2 / 1.8 \mathrm{~Gy} \\
60 / 54 \mathrm{~Gy}\end{array}$ & $\begin{array}{l}400.63 / \\
674.38\end{array}$ & $\begin{array}{l}\text { bed of tu tongue root }+\mathrm{LN} \text { II }+\mathrm{III}+\text { part of IV } \sin / \\
\mathrm{RP}+\text { part of IV } \sin , \mathrm{II}+\mathrm{III}+\text { part of IV dx }\end{array}$ & no \\
\hline 7 & adjuvant & $\begin{array}{l}30 \times 2 / 1.8 \mathrm{~Gy} \\
60 / 54 \mathrm{~Gy}\end{array}$ & $\begin{array}{l}307.67 / \\
432.13\end{array}$ & $\begin{array}{l}\text { bed of tonsilla } \sin +\mathrm{LN} \mathrm{Ib}+\mathrm{II}+\mathrm{III}+\mathrm{IVdx} / \\
\text { bed of tonsilla } \sin +\mathrm{II} \sin \end{array}$ & no \\
\hline 8 & adjuvant & $\begin{array}{l}30 \times 2.1 / 2 / 1.8 \mathrm{~Gy} \\
63 / 60 / 54 \mathrm{~Gy}\end{array}$ & $\begin{array}{l}42.95 / \\
107.21 / \\
233.32\end{array}$ & $\begin{array}{l}\text { LN Ib dx./ } \\
\text { LU II dx./ } \\
\text { LN III+IVdx. }\end{array}$ & $\begin{array}{l}\text { cisDDP } \\
\text { á } 3 \text { weeks } 2 \mathrm{x}\end{array}$ \\
\hline 9 & adjuvant & $\begin{array}{l}30 \times 2.1 / 2 / 1.8 \mathrm{~Gy} \\
63 / 60 / 54 \mathrm{~Gy}\end{array}$ & $\begin{array}{l}68.01 / \\
296.11 / \\
451.6\end{array}$ & $\begin{array}{l}\text { bed of tonsilla sin/ } \\
\text { LN II+III } \sin / \\
\text { LN RP+Ib+IV+Vsin }\end{array}$ & no \\
\hline 10 & adjuvant & $\begin{array}{l}30 \times 2 / 1.8 \mathrm{~Gy} \\
60 / 54 \mathrm{~Gy}\end{array}$ & $\begin{array}{l}254.57 / \\
374.37\end{array}$ & $\begin{array}{l}\text { bed of tonsilla } \sin / \\
\text { LN II+Ib sin./ } \\
\text { LN III sin. }\end{array}$ & no \\
\hline 11 & adjuvant & $\begin{array}{l}30 \times 2.12 / 2 / 1.8 \mathrm{~Gy} \\
63.6 / 60 / 54 \mathrm{~Gy}\end{array}$ & $\begin{array}{l}81.55 / \\
376.13 / \\
758.57\end{array}$ & $\begin{array}{l}\text { bed of tonsilla sin / } \\
\text { LN Ib-III+V } \sin / \\
\text { LN IV } \sin +\text { II+III dx }\end{array}$ & no \\
\hline 12 & adjuvant & $\begin{array}{l}30 \times 2 / 1.8 \mathrm{~Gy} \\
60 / 54 \mathrm{~Gy}\end{array}$ & $\begin{array}{l}107.67 / \\
257.11\end{array}$ & $\begin{array}{l}\text { bed of parotid.gl. dx./ } \\
\text { LN Ib-III dx. }\end{array}$ & no \\
\hline 13 & curative & $\begin{array}{l}30 \times 2.2 / 2 / 1.8 \mathrm{~Gy} \\
66 / 60 / 54 \mathrm{~Gy}\end{array}$ & $\begin{array}{l}86.5 / \\
726.5 / \\
790.97\end{array}$ & $\begin{array}{l}\text { patol.LN II.sin + III.dx/ } \\
\text { LN II-IV bilat. + swallowing axis/ } \\
\text { LN I+RP+V bilat. }\end{array}$ & $\begin{array}{l}\text { cisDDP weekly } \\
4 \mathrm{x}\end{array}$ \\
\hline 14 & adjuvant & $\begin{array}{l}30 \times 2.2 / 2 / 1.8 \mathrm{~Gy} \\
66 / 60 / 54 \mathrm{~Gy}\end{array}$ & $\begin{array}{l}172.93 / \\
525.41 / \\
748.96\end{array}$ & $\begin{array}{l}\text { bed of tonsilla dx./ } \\
\mathrm{LN} \text { Ib+IV+V dx + II+III bilat/ } \\
\mathrm{Ib}+\mathrm{IV}+\mathrm{V} \sin \end{array}$ & no \\
\hline 15 & adjuvant & $\begin{array}{l}30 \mathrm{X} 2 / 1.7 \mathrm{~Gy} \\
60 / 54 \mathrm{~Gy}\end{array}$ & $\begin{array}{l}275.59 \mid \\
630.65\end{array}$ & $\begin{array}{l}\text { bed of larynx/ } \\
\text { LN II-IV bilat. }\end{array}$ & no \\
\hline
\end{tabular}

Gy-gray; PTV - planning target volume; tu - tumor; LN -lymphatic node(s); RP - retropharyngeal lymphnodes; paratrach. - paratracheal lymphnodes; dx-right side; sin - left side; bilat. -bilaterally; gl. - glandula; supracl. - supraclavicular lymphnodes; cisDDP - cisplatin

\section{DISCUSSION}

The promising effect of acupuncture, a TCM method being more and more discussed within the frame of classical evidence-base medicine, was described in this single institutional prospective clinical trial. Patients were randomized to receive standard supportive care \pm acupuncture and better pain control, skin, and mucosal toxicity were observed in this investigational arm.

The use of acupuncture as an additional method for ameliorating the side effects of standard cancer treat- ment was evaluated in limited clinical trials. Menga et al. described the experience with acupuncture in the prevention of RT induced xerostomia in patients treated for nasopharyngeal cancer ${ }^{2}$. Out of 86 enrolled patients, 62 finished follow up 6 months after the end of RT. Patients with acupuncture had lower severity and duration of xerostomia, especially 2 to 6 months after the end of RT. In our presented pilot study, the data for chronic toxicity are still premature and will be published separately. Similar results were also reported by Braga et al. on the smaller cohort of 24 randomized patients where patients in acu- 
Table 3. Individual characteristics of patients from control arm: type of treatment, dose, volume of radiotherapy, ptv, chemotherapy.

\begin{tabular}{|c|c|c|c|c|c|}
\hline & $\begin{array}{l}\text { Curative/ } \\
\text { Adjuvant }\end{array}$ & Radiotherapy dose & $\begin{array}{l}\text { Volume of } \\
\text { prescribed } \\
\text { dose }\left(\mathrm{cm}^{3}\right)\end{array}$ & PTV & Chemotherapy \\
\hline 16 & curative & $\begin{array}{l}30 x 2.2 / 2 / 1.8 / 1.6 \mathrm{~Gy} \\
66 / 60 / 54 / 48 \mathrm{~Gy}\end{array}$ & $\begin{array}{l}132.79 / \\
225.28 / \\
545.15 / \\
583.24\end{array}$ & $\begin{array}{l}\text { larynx/ } \\
\text { LN VI+upper mediastinum over the aortic arch/ } \\
\text { LN II-IV+ bilat./ } \\
\text { upper mediastinum under the aortic arch }\end{array}$ & $\begin{array}{l}\text { cisDDP á } \\
3 \text { week } 2 \mathrm{x}\end{array}$ \\
\hline 17 & adjuvant & $\begin{array}{l}27 \times 2 \mathrm{~Gy}+8 \times 2 \mathrm{~Gy} \\
54 / 70 \mathrm{~Gy}\end{array}$ & $\begin{array}{l}35.28 / \\
62.21\end{array}$ & $\begin{array}{l}\text { nose+upper lip/ } \\
\text { upper lip }\end{array}$ & no \\
\hline 18 & adjuvant & $\begin{array}{l}30 \times 2 / 1.8 \mathrm{~Gy} \\
60 / 54 \mathrm{~Gy}\end{array}$ & $\begin{array}{l}349.91 / \\
462.53\end{array}$ & $\begin{array}{l}\text { bed of tonsilla sin+LN Ib-III sin+RP+IIa dx./ } \\
\text { IIb-III } d x \text {, IV sin }\end{array}$ & no \\
\hline 19 & curative & $\begin{array}{l}35 \times 2 \mathrm{~Gy} \\
70 \mathrm{~Gy}\end{array}$ & 101.29 & Larynx & no \\
\hline 20 & adjuvant & $\begin{array}{l}30 \times 2 / 1.8 \mathrm{~Gy} \\
60 / 54 \mathrm{~Gy}\end{array}$ & $\begin{array}{l}270.62 / \\
348.57\end{array}$ & $\begin{array}{l}\text { oropharynx+LN II-IV dx/ } \\
\text { LN Ib+V dx. }\end{array}$ & no \\
\hline 21 & adjuvant & $\begin{array}{l}30 \times 2 / 1.8 \mathrm{~Gy} \\
60 / 54 \mathrm{~Gy}\end{array}$ & $\begin{array}{l}188.66 / \\
372.97\end{array}$ & $\begin{array}{l}\text { bed of uvula+LN RP+II sin/ } \\
\text { LN Ib+III-V sin }\end{array}$ & no \\
\hline 22 & adjuvant & $\begin{array}{l}30 \times 2 \mathrm{~Gy} \\
60 \mathrm{~Gy}\end{array}$ & 90.96 & bed of tonsilla sin & no \\
\hline 23 & adjuvant & $\begin{array}{l}33 \times 2.12 / 2 / 1.9 / 1.7 \mathrm{~Gy} \\
61.48 / 58 / 55.1 / 49.3 \mathrm{~Gy}\end{array}$ & $\begin{array}{l}125.94 / \\
438.41 / \\
663.76 / \\
913.37\end{array}$ & $\begin{array}{l}\text { bed of tonsilla sin/ } \\
\text { LN Ib+II sin + bed of tonsilla sin with rim/ } \\
\text { LN RP bilat.+III-V sin } \\
\text { LN Ib-V dx }\end{array}$ & $\begin{array}{l}\text { cisDDP á } \\
3 \text { weeks } 2 \mathrm{x}\end{array}$ \\
\hline 24 & curative & $\begin{array}{l}33 \times 2.12 / 1.9 \mathrm{~Gy} \\
69.96 / 62.7 \mathrm{~Gy}\end{array}$ & $\begin{array}{l}125.10 / \\
391.19\end{array}$ & $\begin{array}{l}\text { larynx/ } \\
\text { LN III bilat. }\end{array}$ & no \\
\hline 25 & adjuvant & $\begin{array}{l}30 \times 2 / 1.8 \mathrm{~Gy} \\
60 / 54 \mathrm{~Gy}\end{array}$ & $\begin{array}{l}358.04 / \\
972.02\end{array}$ & $\begin{array}{l}\text { bed of larynx/ } \\
\text { II-IV bilat. }\end{array}$ & no \\
\hline 26 & adjuvant & $\begin{array}{l}30 \times 2.1 / 2 / 1.8 \mathrm{~Gy} \\
63 / 60 / 54 \mathrm{~Gy}\end{array}$ & $\begin{array}{l}371.27 / \\
638.67 / \\
679.34\end{array}$ & $\begin{array}{l}\text { bed of tonsilla dx + bed of patol.LN/ } \\
\text { LN RP+Ib-V dx/ } \\
\text { II-III } \sin \end{array}$ & $\begin{array}{l}\text { cisDDP á } \\
3 \text { weeks } 2 \mathrm{x}\end{array}$ \\
\hline 27 & curative & $\begin{array}{l}\text { 35/30x2 Gy; } \\
70 / 60 \mathrm{~Gy}\end{array}$ & $\begin{array}{l}271.72 / \\
718.79\end{array}$ & $\begin{array}{l}\text { patol.LN bilat./ } \\
\text { naso-oropharynx+LN RP-V bilat. }\end{array}$ & CBDCA weekly $7 \mathrm{x}$ \\
\hline 28 & adjuvant & $\begin{array}{l}33 \times 2 \mathrm{~Gy} \\
66 \mathrm{~Gy}\end{array}$ & 144.07 & Larynx & no \\
\hline 29 & curative & $\begin{array}{l}35 \times 2 / 30 \times 1.8 \mathrm{~Gy} \\
70 / 54 \mathrm{~Gy}\end{array}$ & $\begin{array}{l}213.07 / \\
441.24\end{array}$ & $\begin{array}{l}\text { larynx+LN at larynx/ } \\
\text { LN III+IV bilat. }\end{array}$ & no \\
\hline 30 & curative & $\begin{array}{l}33 \times 2 / 1.9 / 1.7 \mathrm{~Gy}+3 \times 2 \mathrm{~Gy} \\
72 / 66 / 62.7 / 56.1 \mathrm{~Gy}\end{array}$ & $\begin{array}{l}82.03 / \\
208.55 / \\
540.24 / \\
613.54\end{array}$ & $\begin{array}{l}\text { boost tumor/ } \\
\text { tu of oral cavity floor/ } \\
\text { LN upper II/ } \\
\text { LN Ib+II+III bilat }\end{array}$ & $\begin{array}{l}\text { cisDDP á } \\
3 \text { weeks } 2 \mathrm{x}\end{array}$ \\
\hline
\end{tabular}

PTV - planning target volume; Gy - gray; LN - lymphatic node(s); bilat. - bilaterally; dx - right side; sin - left side; patol. - pathological; RP retropharyngeal lymphnodes; tu - tumor; cisDDP - cisplatin; CBDCA - carboplatine

Table 4. Treatment details.

\begin{tabular}{lcc}
\hline Characteristic & Control arm \\
& $\mathrm{n}=15$ & $\begin{array}{c}\text { Acupuncture arm } \\
\mathrm{n}=15\end{array}$ \\
\hline Radiotherapy & & $15,100 \%$ \\
finished as planned $(\mathrm{n} ; \%)$ & $15,100 \%$ & $60-70 \mathrm{~Gy}$ \\
total dose & $60-70 \mathrm{~Gy}$ & $1.7-2.12$ \\
daily dose & $1.7-2.12$ & $100 \%$ \\
VMAT technique & $100 \%$ & 2 patients $(13 \%)$ \\
Chemotherapy & 5 patients $(33 \%)$ & 1 patient $(7 \%)$ \\
cDDP weekly & 0 & 1 patient $(7 \%)$ \\
cDDPdays 1, 22, 43 & 4 patients $(27 \%)$ & 0 \\
CBDCA weekly & 1 patient $(7 \%)$ & \\
\hline
\end{tabular}

VMAT: Volumetric Modulated Arc Therapy; cDDP: cisplatin; CBDCA: carboplatin; Gy: grey 
puncture arm developed significantly lower xerostomia ${ }^{3}$. After RT completion, clinical response was assessed in all patients by sialometry, measuring the resting (RSFR) and stimulated (SSFR) salivary flow rates, and by the visual analogue scale (VAS) regarding dry mouth-related symptoms. Patients in the acupuncture group showed improved salivary flow rates (RSFR, SSFR; $P<0.001$ ) and decreased xerostomia-related symptoms (VAS, $P<0.05)$ compared with patients in the control group ${ }^{3}$. The supporting role of acupuncture was also investigated in the treatment of other cancer types. For example, in patients with breast cancer treated by hormonotherapy and suffering from hot flashes, the systematic review and metaanalysis of 18 studies showed the important role of acupuncture in therapy of hot flashies ${ }^{4}$.

Despite its prospective nature, our study has several limitations apart from general limitations related to reporting of pilot data before completion of patient recruitment (for example slight imbalance in the aim of radiotherapy with more patients with curative RT in control arm and difference in other characteristics as discussed below). The most important is the inability to provide placebo (or sham device) controlled trial, thus, it is not possible to exclude possible placebo bias effect. On the other hand, patients developed objectively measured improvement in the toxicity, which is important for daily perception of treatment by the individual patient. Thus, increased treatment tolerance may assure the treatment continuation without breaks, which is imperative for head and neck radiation therapy. Non-believers in TCM acknowledge the no side effects of acupuncture by fine needles insertions, except possible discomfort from punctures (however what is widely accepted by motivated patients).

Another bias may flow from tobacco and alcohol abuse, which is very common in head and neck patients. These addictive substances may alleviate the symptoms in a certain way, on the other hand, the head and neck patients usually have develope a considerable abuse already before the treatment initiation. This fact decreases potential symptoms mitigating effect of these substances. Thus, the continual intake of these substances before, during and after the treatment does not probably impact on the acupuncture effect.

The other limitation of this interim analysis of first 30 enrolled patients is an unbalanced distribution of patients according to age (with younger patients in acupuncture arm 52 vs 60 years). Whether this unbalance will remain in final data analysis after enrollment of all 60 planned patients, separate statistical analyses of different age cohorts will be valuable. The same applies to smoking history of enrolled patients.

\section{CONCLUSION}

In conclusion, we confirmed the feasibility of testing the role of acupuncture in the frame of the prospective randomized trial. In this pilot data report of first 30 patients, acupuncture leads to lower pain and better skin and mucosal toxicity after the (chemo)radiotherapy of head and neck cancer. Enrollment of other patients is needed to confirm observed differences with higher statistical power. In general, description and validation of proposed theoretical effects of acupuncture using scientific approaches will further enhance acceptance of this method by both patients and health care providers.

Acknowledgement: This work was supported by the Ministry of Health of the Czech Republic, [grant No. 15-33590A], MH CZ-DRO (MMCI, 00209805) and supported by project MSMT - NPU I - LO1413.

Author contributions: RD, TK, MS, ISPS,OS: development of methodology and general research concept, statistical analysis, manuscript writing; RD: acupuncture; IS: statistical analysis; MS, PS, OS: oncology treatment; TK and MS: collaboration on manuscript writing, literature search and data interpretation. All authors contributed to the first draft's preparation and read and approved the final manuscript.

Conflict of interest statement: The authors state that there are no conflicts of interest regarding the publication of this article.

\section{REFERENCES}

1. Santuray RT, Johnson DE, Grandis JR. New Therapies in Head and Neck Cancer. Trends Cancer 2018;4(5):385-96. doi: 10.1016/j. trecan.2018.03.006

2. Meng Z, Garcia MK, Hu C, Chiang J, Chambers M, Rosenthal DI, Peng H, Zhang Y, Zhao Q, Zhao G, Liu L, Spelman A, Palmer JL, Wei $\mathrm{Q}$, CohenL. Randomized controlled trial of acupuncture for prevention of radiation-induced xerostomia among patients with nasopharyngeal carcinoma. Cancer 2012;118(13):3337-44. doi: 10.1002/ cncr.26550

3. Braga FP, Lemos Junior CA, Alves FA, Migliari DA. Acupuncture for the prevention of radiation-induced xerostomia in patients with head and neck cancer. Braz Oral Res 2011;25(2):180-5.

4. Wang XP, Zhang DJ, Wei XD, Wang JP, Zhang DZ. Acupuncture for the relief of hot flashes in breast cancer patients: A systematic review and meta-analysis of randomized controlled trials and observational studies. J Cancer Res Ther 2018;14(Suppl)S600-S608. doi: 10.4103/0973-1482.183174

5. Brizhik L, Chiappini E, Stefanini P, Vitiello G. Modeling Meridians Within the Quantum Field Theory. J Acupunct Meridian Stud 2019;12(1):29-36. doi: 10.1016/j.jams.2018.06.009

6. Dymackova R, Slama O. Acupuncture in thetreatment of symptoms of oncological diseases in the Western world. Klin Onkol 2014;27(4):291-3.

7. Chan MWC, Wu XY, Wu JCY, Wong SYS, Chung VCH. Safety of Acupuncture: Overview of Systematic Reviews. SciRep 2017;7:3369. doi:10.1038/s41598-017-03272-0

8. Grégoire V, Lefebvre JL, Licitra L, Felip E; EHNS-ESMO-ESTRO Guidelines Working Group. Squamous cell carcinoma of the head and neck: EHNS-ESMO-ESTRO Clinical Practice Guidelines for diagnosis, treatment and follow-up. Ann Oncol 2010;21(Suppl 5):vi184vi186. doi: 10.1093/annonc/mdq185

9. Chan AT, Grégoire V, Lefebvre JL, Licitra L, Hui EP, Leung SF, Felip E. Nasopharyngeal cancer: EHNS-ESMO-ESTRO Clinical Practice Guidelines for diagnosis, treatment and follow-up. Ann Oncol 2012;23(Suppl 7):vii83-vii85.

10. Niu X, Yang X, Fu C., Three-dimensional motion of the radialartery and thespatiality, rhythmicity, formability and intensity of TCM pulse diagnosis. Afr J Tradit Complement Altern Med 2013;10(3):550-60. eCollection 2013

11. RTOG Foundation, inc., Cooperative Group Common Toxicity Criteria. Available from: https://www.rtog.org/ResearchAssociates/ AdverseEventReporting/CooperativeGroupCommonToxicityCriteria. aspx 